\title{
O CONCEITO DE HISTÓRIA EM KARL MARX
}

\author{
Roberto Nunes Junior ${ }^{1}$ \\ Universidade Federal de Pernambuco (UFPE) \\ (D) https://orcid.org/0000-0003-1385-0496
}

\begin{abstract}
RESUMO:
O presente trabalho pretende discutir o conceito de história em Karl Marx a partir do confronto com a teoria do "fim da história" de Francis Fukuyama. No contexto histórico de queda do comunismo na União Soviética e no Leste Europeu, o autor americano introduz sua concepção sobre a vitória da democracia liberal como o momento culminante da história da humanidade. Pretendendo, assim, colocar-se como herdeiro de uma visão hegeliana da história. Ora, em que medida podemos considerar um sistema como o defendido por Fukuyama como sendo o objetivo de toda a história da humanidade? Mais ainda, em que medida podemos considerar que há um objetivo na história da humanidade? Procuro mostrar como a concepção marxista da história responde a estas duas questões.
\end{abstract}

PALAVRAS-CHAVE: Karl Marx; Francis Fukuyama; Teoria da história.

\section{THE CONCEPT OF HISTORY IN KARL MARX}

\begin{abstract}
:
This essay wishes to debate the concept of History in Karl Marx's work, in opposition to the "end of History" theory proposed by Francis Fukuyama. In a historic setting that involved the end of the communist era in the Soviet Union and in Eastern Europe, the American author introduces his ideas about the victory of liberal democracy being the culminating point in the history of humanity. Well, to what extent is it possible to consider a system like the one advocated by Fukuyama as the ultimate goal of mankind? Furthermore, to what extent can we consider that there actually is a goal that humanity is seeking to achieve? This essay intends to answer these questions through a Marxist understanding of History.
\end{abstract}

KEYWORDS: Karl Marx; Francis Fukuyama; Theory of History.

1Doutorando em filosofia pela Universidade Federal de Pernambuco (UFPE), Recife Brasil. Bolsista CAPES. E-mail: jr.robertonunes@gmail.com 


\section{Introdução}

Nas diversas polêmicas no âmbito da teoria de Marx, a sua concepção de história certamente figura entre as principais. Ao afirmar que a história era um incessante processo de desenvolvimento de forças produtivas e relações de produção, Marx inverteu a lógica até então posta e colocou o trabalho como fator fundamental deste processo.

Em obras como o Manifesto Comunista (1847) e A ideologia Alemã (1845-46), Marx esboça a teoria de que o desenvolvimento das forças produtivas se dá dentro um sistema determinado de relações de produção (escravismo, feudalismo, capitalismo). A questão é que essas mesmas relações de produção se tornam, em um determinado momento, entrave para o contínuo desenvolvimento das forças produtivas. É quando se abriria um momento revolucionário no qual a disputa entre as classes antagônicas da sociedade faz emergir uma nova forma de estrutura socioeconômica.

Pois bem, esta é a leitura que Marx fez da história até aquele momento, mas, e o comunismo? Seria ele visto como uma necessidade da história ou "apenas" como uma de suas possibilidades? A resposta a essa pergunta não só define se Marx pode ser encarado como um defensor de uma teleologia na história, mas define o próprio caráter que tem a ação do indivíduo dentro de sua teoria.

Evidentemente, o otimismo que permeou o movimento comunista no século passado foi dissipado junto com a queda da URSS, o que abriu espaço para uma contraofensiva teórica, e ideológica, por parte dos defensores do capitalismo. E é partir deste confronto que pretendo discutir a questão colocada acima.

\section{Francis Fukuyama e o fim da história}

Foi o cientista político americano Francis Fukuyama que, em um contexto de queda do socialismo na antiga União Soviética e no Leste Europeu, afirmou em um ensaio chamado "O fim da história" e no livro intitulado $O$ fim da história e o último homem que, no que diz respeito a grandes transformações socioeconômicas, a história da humanidade havia chegado ao fim. Segundo Fukuyama, a democracia liberal seria o ponto de chegada de um processo incessante de busca por uma sociedade racional e livre.

Essas declarações geraram inúmeras discussões e críticas, vindas das mais diversas correntes do pensamento político da época. No entanto, consideramos extremamente atual e relevante retomar o debate em torno desse tema. A própria compreensão de democracia liberal como fase superior do capitalismo é sempre questionada em momentos de crise 
econômica, quando a intervenção do Estado se torna um instrumento primordial na recuperação de países atingidos pelos efeitos do sistema.

Apesar de podermos facilmente estender a possibilidade da democracia liberal como finalidade da história ao sistema capitalista - tanto em sua totalidade quanto em suas diversas nuances - aqui pretendemos formular a questão em torno da proposta original de Fukuyama, ou seja, no que tange à democracia liberal.

Para tanto, temos duas questões principais a problematizar: (1) a democracia liberal realmente pode ser considerada uma forma de governo em que a liberdade e a razão se realizam plenamente, mais do que em qualquer outra sociedade conhecida até hoje? (2) A própria noção de história pode ser entendida como um "progresso para determinado fim"?

Fukuyama retoma Hegel para afirmar que o principal objetivo do ser humano é a busca pelo reconhecimento e que isso funcionaria como um verdadeiro "motor da história". Mas, segundo Fukuyama, Hegel estaria enganado quanto ao destino final dessa história. De acordo com o cientista político, a humanidade faria mais um progresso rumo ao que, agora sim, seria o último e definitivo estágio do caminhar histórico. A derrocada do projeto comunista no fim do século XX confirmaria essa hipótese. Justamente o contrário do que pensava, e do que sequer poderia imaginar Hegel:

\footnotetext{
Com as revoluções francesa e americana, Hegel conclui que a história chegou ao fim porque a aspiração que impulsionou o processo histórico - a luta pelo reconhecimento - está agora satisfeita numa sociedade caracterizada pelo reconhecimento universal e recíproco. Nenhum outro ajuste das instituições sociais e humanas é mais capaz de satisfazer essa aspiração e, portanto, não é possível nenhuma outra mudança histórica progressiva (FUKUYAMA, 1992, p.19).
}

Como sabemos, o século passado provou que a história estava longe de chegar a um ponto fixo de estabilidade que nos permitisse decretar o fim de suas possibilidades. Duas guerras mundiais, revoluções socialistas em todos os continentes e uma Guerra Fria que colocou duas superpotências nucleares em rota de colisão não deixaram dúvidas quanto às incertezas que permeiam a história. Entretanto, passado o momento de guerras e revoluções, Fukuyama retoma o argumento de Hegel para afirmar que aquele estágio imaginado pelo filósofo alemão se concretizava agora, com a vitória da democracia liberal sobre o comunismo. Para ele, somente nessa sociedade a busca do homem por reconhecimento teria êxito. Não se trata, portanto, simplesmente da tentativa de obter melhores condições materiais de vida. A luta contra a exploração e subjugação teria como meta e, consequentemente, como recompensa, a satisfação desse desejo de reconhecimento. Nesse sentido, ele afirma: 
A democracia liberal substitui o desejo irracional de ser reconhecido como maior que os outros pelo desejo racional de ser reconhecido como igual. Um mundo feito de democracias liberais, então, teria menor incentivo para guerras, uma vez que haveria o reconhecimento recíproco da legitimidade entre todas as nações (Ibid., p. 21).

Ou seja, Fukuyama trabalha com um conceito de democracia liberal em que esta, além de racional, seria igualitária. Haveria no homem um "desejo irracional", mas naturalizado, de se reconhecer e ser reconhecido como superior aos demais. Somente na democracia liberal, ou seja, em uma sociedade em que predomina a razão, essa irracionalidade seria substituída por um reconhecimento de igualdade. Isso se daria não apenas no que diz respeito ao reconhecimento de cada ser humano, mas também no que diz respeito ao reconhecimento das próprias nações, o que acarretaria um "menor incentivo para guerras". É importante frisar que o que aconteceria não seria o fim das guerras, mas o "menor incentivo" para suas ocorrências, desde que o mundo seja tomado por democracias liberais.

Fukuyama identifica duas questões que poderiam fazer sucumbir a sua hipótese: a primeira seria uma crítica da direita, que está relacionada ao estatuto da igualdade colocado pela democracia liberal. Não estaria esse estatuto em nítida contradição com a própria natureza humana, que deseja e quer ser reconhecida como superior às demais? Não cairia, dessa forma, no mesmo erro do comunismo, que considera que todos os seres humanos são iguais? Nesse ponto, a crítica da esquerda tem o sentido oposto, incidindo sobre as desigualdades sociais, que permanecem sob o sistema capitalista. E o seu amparo é a defesa de uma sociedade em que as desigualdades sejam amenizadas ou eliminadas. Em resposta a isso, diz Fukuyama:

O problema da desigualdade continuará a preocupar as sociedades liberais ainda por muitas gerações porque em certo sentido é insolúvel dentro do contexto do liberalismo. Mesmo assim parecem ser "contradições" menos fundamentais na nossa ordem atual do que os descontentamentos que se manifestam à direita, isto é, concernentes à desejabilidade do reconhecimento igual como um fim em si mesmo (Ibid., p. 350).

Ou seja, a crítica da esquerda é destinada à democracia liberal, que não ofereceria horizontes para a superação das desigualdades sociais, pois, como o próprio autor norte-americano afirma, a desigualdade é um problema "insolúvel dentro do contexto do liberalismo". Por outro lado, a crítica que a direita realiza classifica como pretensão estabelecer que todos são iguais e afirma que isso iria contra a própria natureza do ser humano.

Por considerar esta última crítica como mais fundamental à ordem democrático-liberal, Fukuyama retorna a Platão e tenta identificar nele o cerne de uma teoria que justifique o desejo de reconhecimento como inato 
ao homem. É nesse sentido que ele alia a teoria da história de Hegel à teoria da natureza humana de Platão:

O desejo de reconhecimento pode parecer, a princípio, um conceito pouco familiar, mas é tão antigo quanto a tradição da filosofia política ocidental, e constitui uma parte bem conhecida da personalidade humana. Foi descrito pela primeira vez por Platão na República quando afirmou que a alma tem três partes: a parte do desejo, a parte racional e uma parte que ele chamou de thymos, ou o "espírito" (...) o desejo de reconhecimento e as emoções que o acompanham, de ira, vergonha e orgulho fazem parte da personalidade humana essencial para a vida política. Segundo Hegel, são essas emoções que impulsionam todo o processo histórico (FUKUYAMA, 1992, p. 17-18).

Para Fukuyama, a terceira parte da alma (thymos) foi abandonada ao longo da história. Inicialmente, a partir de Hobbes e Locke que "procuraram erradicar completamente a noção de thymos da vida política, substituindo-o por uma combinação de desejo e razão" (Ibid., p. 229). Esse abandono foi sendo cristalizado à medida que o capitalismo foi se estabelecendo como sistema socioeconômico predominante no mundo. Fukuyama contrapõe desejo a thymos, afirmando que "o mundo econômico moderno só pôde emergir depois que o desejo foi liberado, por assim dizer, à custa de thymos" (Ibid., p. 234). Thymos visaria à glória, à honra e ao reconhecimento pessoal. O desejo, nesse sentido colocado por Fukuyama, estaria relacionado aos ganhos econômicos.

Mas a noção de thymos pode ser traduzida ainda de duas formas distintas. Fukuyama recorre ao prefixo megalo (megalo-thymia) para conotar um "desejo de ser reconhecido como superior aos demais". Quando o sentido é o "desejo de ser reconhecido como igual aos demais", ele se expressa através do prefixo iso (iso-thymia). Desse modo, o desafio seria buscar o equilíbrio de thymos entre os dois polos.

Entretanto, Fukuyama entende que o extremo condenado foi justamente o da megalothymia, que teria sido substituída de duas maneiras: a primeira seria a "economização" da vida, ou seja, o ganho econômico a despeito de qualquer outro valor; a segunda é a exacerbação da isothymia (Ibid., p. 235).

É nesse sentido que a crítica colocada pela direita, da preocupação com a "desejabilidade do reconhecimento igual como um fim em si mesmo", assume, para Fukuyama, um caráter mais urgente e fundamental:

Sem ser preciso, por enquanto, compartilhar o ódio de Nietzsche pela democracia liberal, podemos fazer uso de suas percepções a respeito do difícil relacionamento entre a democracia e o desejo de reconhecimento, isto é, na medida em que a democracia liberal consegue expulsar a megalothymia da 
vida, substituindo-a pelo consumo racional, passamos a ser últimos homens. Mas os seres humanos se rebelarão contra essa ideia. Ou seja, vão se rebelar contra a ideia de serem membros indiferenciados de um Estado universal e homogêneo, cada um exatamente como o outro, não importa em que lugar do globo possam viver (Ibid., p. 378) .

Aqui, claramente, democracia assume o sentido de liberdade e igualdade, remetendo ao desejo de reconhecimento. Fukuyama desconsidera a questão das desigualdades como um problema que possa levar a democracia liberal ao fim. Logo, o perigo estaria na satisfação do nosso desejo racional de reconhecimento igualitário; a revolta poderia ser gerada quando não tivéssemos mais nada pelo que lutar.

É como se a democracia liberal, conseguindo estabelecer o estatuto da igualdade entre os homens, tivesse que ceder um pouco à natureza humana e abrisse, então, espaço para a megalothymia, sob o risco de se perder a própria efetividade da democracia. Caso contrário, padeceríamos no mar tedioso da homogeneidade e da massificação. Podemos chegar à conclusão de que, quando Fukuyama afirma que "a democracia liberal substitui o desejo irracional de ser reconhecido como maior que os outros pelo desejo racional de ser reconhecido como igual", isso não significa necessariamente uma vantagem, pois traria consigo a "contradição que a democracia liberal ainda não resolveu": os seres humanos careceriam de "ideias pelas quais possam viver e morrer", já que a "vida do consumo racional é aborrecida" (Ibid., p. 378).

Fukuyama afirma estar convencido de que o excesso de isothymia era o maior perigo para a democracia liberal, citando como prova o fracasso da tentativa do comunismo em criar um ambiente de igualdade entre os homens:

\begin{abstract}
A democracia liberal poderia, a longo prazo, ser subvertida internamente por um excesso de isothymia ou por um excesso de megalothymia - isto é, o desejo fanático de reconhecimento igual. A intuição me diz que o primeiro é que constituirá no fim a maior ameaça à democracia. Uma civilização que aceita de bom grado a isothymia sem freio, que procura fanaticamente eliminar qualquer manifestação de reconhecimento desigual, em pouco tempo chegará aos limites impostos pela própria natureza. Estamos no fim de um período no qual o comunismo tentou usar o poder do Estado para eliminar a desigualdade econômica e com isso solapou as bases da vida econômica moderna (Ibid., p. 378-379).
\end{abstract}

Obviamente, Fukuyama está falando em um contexto histórico de queda do socialismo e de consequente avanço do neoliberalismo. Mesmo sem referência ao termo, Fukuyama está defendendo uma determinada etapa do neoliberalismo ao falar de democracia liberal, o que se torna mais nítido 
por sua vinculação ao Departamento de Estado dos Estados Unidos. Não obstante, as críticas à ideia de o Estado ser usado para "eliminar as desigualdades econômicas" e a argumentação de contraposição às "bases da vida econômica moderna" podem ser interpretadas como justificativas à mínima intervenção estatal na economia, princípio econômico do neoliberalismo.

Na mesma medida, a isothymia é situada como o maior perigo para a estabilidade da democracia liberal, pois o seu excesso poderia fazer regressar velhos "sonhos de igualdade fanática" e, com isso, colocar em risco a própria natureza humana, que quer e necessita ser desigual.

Se essa desigualdade é então uma exigência da natureza humana, como poderia conviver com um sistema que se pretende detentor do "desejo racional por igualdade"? Ainda que isso seja possível, seria a democracia liberal a única capaz de equilibrar a isothymya e a megalothymia e usá-las de forma benéfica para a sociedade? De que forma isso seria possível? Responde Fukuyama:

\footnotetext{
Os esforços da democracia para abolir a megalothymia ou para convertê-la em isothymia têm sido, na melhor das hipóteses, incompletos. $\mathrm{Na}$ verdade, a saúde e a estabilidade da democracia a longo prazo repousam na qualidade e no número de escoadouros para a megalothymia, que estão à disposição de seus cidadãos (Ibid., p. 379-380).
}

Quando Fukuyama fala em esforços para converter a megalothymia em isothymia, é à esquerda e ao seu projeto de igualdade que ele está criticando. Contudo, ele já não pensa que seja saudável a ideia de uma sociedade democrática liberal igualitária, não pela sua impossibilidade, mas por ser ela contrária à própria natureza humana, e por trazer consigo a padronização do homem. Ou seja, trata-se de uma sociedade "que não teria muito dinamismo econômico: as artes e a indústria seriam vulgares e a tecnologia de segunda classe" (Ibid., p. 379).

Em relação ao excesso de megalothymia, para que a democracia liberal tenha êxito e segurança faz-se necessária a criação de "escoadouros" para onde o desejo de ser superior possa ser canalizado em medidas que, inclusive, ajudariam a dinamizar e manter viva a sociedade. Mas, somente nela, na democracia liberal, seria factível criar as condições para que esses "escoadouros" sejam possíveis e em número suficiente, pois ficaria estabelecida a razão como predominante e reguladora da atividade humana. Para Fukuyama, a igualdade teria que abrir espaços para a liberdade. Ao contrário do que, segundo ele, aconteceria no comunismo, uma vez que ali a igualdade não só tira o espaço da liberdade, como também a aniquila.

Os Estados Unidos da América seriam, dessa forma, o modelo de sociedade ideal, na qual a megalothymia é usada na medida certa. Os escoadouros nos quais a megalothymia do homem dispensaria seriam o 
empreendedorismo, a ambição, a ganância, etc. Assim, aqueles que desejam ser reconhecidos como maiores do que os demais encontram o ambiente ideal e, se não o encontram no esporte, na ciência ou em qualquer outra profissão, os escoadouros podem ser encontrados até na política externa. Vejamos o que diz Fukuyama sobre isso:

\begin{abstract}
A guerra dos Estados Unidos em 1991 no golfo pérsico indica que um politico como George Bush, inconsistente e limitado nos problemas internos, pode, mesmo assim, criar novas realidades no cenário mundial, exercendo os poderes constitucionais do seu mandato como chefe de Estado e comandante-em-chefe das forças armadas. Embora o número de presidências imperfeitas tenha tirado o brilho do cargo, um sucesso presidencial como a vitória numa guerra resulta num certo grau de reconhecimento público, que é completamente inacessível ao empresário ou industrial de maior sucesso. Desse modo, a politica democrática continuará a atrair os que ambicionam ser reconhecidos como maiores do que os outros (Ibid., p. 382-383).
\end{abstract}

Mais adiante, completa dizendo que "é provavelmente saudável para as democracias liberais que o Terceiro Mundo exista para absorver as energias e ambições desse tipo de homens; se é bom para o Terceiro Mundo é outra história" (Ibid., p. 383). Por conseguinte, podemos chegar a duas conclusões: ou no Terceiro Mundo não há países com democracia liberal, ou a tese de que em um mundo dominado por democracias liberais haveria "pouco incentivo para as guerras" foi solapada pela força de thymos de alguns personagens que, ocupando cargos que lhes dessem as condições, poderiam provocar uma invasão e uma guerra.

Mais de vinte anos após a publicação do ensaio $O$ fim da história, seguido do livro $O$ fim da história $e$ o último homem, poucos dão credibilidade à tese de que a história teria chegado ao fim com a democracia liberal. A sociedade racional anunciada por Fukuyama, que levaria o homem ao reconhecimento igualitário, sucumbiu perante o que ele próprio denominou de "força timótica da natureza humana".

A megalothymia não é apenas uma permissão controlada do capitalismo para que o homem não se afaste de sua natureza, mas a própria regra do capitalismo. O Estado, em vez de garantir as condições para a igualdade, precisa oferecer as condições para a desigualdade e a racionalidade disso é bastante questionável.

O problema é que o conceito utilizado, da forma como é retomado por Fukuyama, não consegue explicar a insatisfação crescente e coletiva em relação a problemas comuns, como a crise ecológica, as altas jornadas de trabalho e a precarização do mesmo, além da própria alienação do homem em relação ao seu meio de trabalho e ao produto deste. Este último 
problema, o da alienação, é desconsiderado por Fukuyama quando este aborda, por exemplo, o problema do reconhecimento.

\section{O conceito de história em Karl Marx}

O filósofo alemão Karl Marx trabalha no sentido oposto do colocado pelo autor americano. Para ele, o capitalismo é justamente o momento em que o homem deixa de se reconhecer. Afirma ainda que, no capitalismo, mais do que em qualquer outra sociedade, a propriedade privada faz com que o homem não se reconheça e, portanto, não se realize em seu trabalho, pois este é uma atividade externa a ele. Dessa forma, o faz "negar a si mesmo, ter um sentimento de sofrimento em vez de bem-estar, não desenvolver livremente suas energias mentais e físicas, mas ficar fisicamente exausto e mentalmente deprimido" (MARX, 2004, p. 23).

Se chegarmos à conclusão de que a democracia liberal não pode ser considerada uma sociedade em que a busca do homem por reconhecimento seja, enfim, realizada, criando um ambiente de igualdade e liberdade (mesmo que, como já vimos, essa relação entre igualdade e liberdade não seja totalmente harmônica), resta-nos a seguinte pergunta: existiria alguma forma de sociedade que possa ser considerada como estágio final do processo histórico?

Antes de respondermos a essa pergunta, precisamos problematizar a própria noção de processo histórico. Novamente, começamos com Fukuyama:

Contudo, o que eu sugeria não era o fim da ocorrência de eventos, nem dos fatos grandes e importantes, mas da história, ou seja, da história como um processo único coerente e evolutivo considerando a experiência de todos os povos em todos os tempos (FUKUYAMA, 1992, p.12).

Fukuyama distingue a "ocorrência de eventos", assim como os "fatos grandes e importantes", do processo histórico e de suas mais diversas formações. Apoiando-se na tradição hegeliana, pleiteia uma racionalidade que, usando inclusive os eventos e fatos importantes, levaria a humanidade a um estágio tal de satisfação. O que pretendemos aqui é problematizar a visão que Fukuyama assume, uma vez que ele próprio, em entrevista ao programa Roda Viva ${ }^{2}$, evitou falar sobre a manutenção do termo "fim da história". Quando perguntado sobre como queria ser lembrado, disse que "como o homem que previu a universalização da democracia pelo mundo".

2

http://www.rodaviva.fapesp.br/materia_busca/214/bric/entrevistados/francis_fukuyama_20 06.htm. Acessado em 01 de outubro de 2015. 
Ainda que, em certo sentido, possamos identificar essa universalização como a consolidação da finalidade da história analisada anteriormente, o relativo abandono do termo "fím da história" revela, no mínimo, uma insegurança sobre o arcabouço teórico que o sustentava.

Mas a tese de que o processo histórico se dá de forma teleológica é uma polêmica que permeia a própria interpretação dos textos de Marx. A história não estaria sujeita, em seus textos, a certo determinismo econômico? Este trabalho, no entanto, alinha-se com aqueles que entendem o conceito de história em Marx de outra forma. Conceito este que abarca, também, a responsabilidade do sujeito. Analisando o prefácio de $O$ Capital, vejamos o que diz o filósofo Claudio Oliveira:

\begin{abstract}
Marx afirma ainda que sua concepção do desenvolvimento da formação econômico-social como um processo históriconatural exclui, mais do que qualquer outra, a responsabilidade do indivíduo por relações, das quais ele continua sendo, socialmente, criatura, por mais que, subjetivamente, se julgue acima delas (OLIVEIRA, 2005, p. 233).
\end{abstract}

Mais à frente, porém, o próprio Marx deixaria em aberto a questão de como seria possível uma revolução social sem a intervenção decisiva dos indivíduos. Ainda no mesmo prefácio, afirma que a "sociedade atual não é um ser petrificado, mas um organismo capaz de mudar, constantemente submetido a processos de transformação" (MARX, apud OLIVEIRA, 2005, p. 234). Por conseguinte, Oliveira indaga: "Como tal transformação poderia se dar a não ser reinserindo aí aquilo que, algumas linhas acima, Marx tinha excluído: 'a responsabilidade do indivíduo por relações, das quais ele continua sendo, socialmente, criatura?" (Ibid., p. 233).

Diante disso, podemos entender a história para além do "determinismo econômico". Em Marx, encontramos brechas para pensar a ação do sujeito como elemento fundamental na transformação social. Mas como pensar esse rumo, esse caminho que a história seguiria?

Não há dúvida de que existe uma inteligibilidade na história. Mas será mesmo que essa inteligibilidade pode ser projetada para o futuro, de modo a antecipar os acontecimentos e o próprio processo histórico? E, além disso, não apenas projetar o próximo passo da história, mas afirmar que ele poderia ser o último? Ou seria essa inteligibilidade apenas possível em relação ao passado, ou seja, à série de eventos causais que nos trouxeram até onde estamos e que, desse modo, seria plenamente possível identificar neles os motivos e situações que os tornaram necessários? Em outras palavras, esta necessidade só poderia ser identificada e justificada pela razão posteriormente à ocorrência do fato.

Vejamos o que diz Oliveira em seu texto Economia marxista $e$ economia freudiana ou política e pulsão: 


\begin{abstract}
Marx se serve igualmente (como o faz muitas vezes Freud) do exemplo das espécies animais para explicitar essa estrutura temporal. Ele diz: "O que nas espécies animais inferiores indica uma forma superior não pode, ao contrário, ser compreendido senão quando se conhece a forma superior". Em outras palavras, o presente não é imediatamente explicado pelo passado. Ao contrário, só o presente pode explicar o passado, o qual, através dessa explicação presente, só depois pode se mostrar como tendo sido o passado do presente que temos hoje. Mas o "só depois" indica que essa causalidade não pode ser estabelecida a priori, mas apenas a posteriori, nachträglich. É o que Marx cunha em sua célebre fórmula: "A anatomia do homem é a chave da anatomia do macaco", que para ele significa: "A economia burguesa é a chave da economia da Antiguidade" (OLIVEIRA, 2008, p. 53).
\end{abstract}

Nesse texto, o autor analisa de que forma o surgimento de Freud deu outro significado a Marx. Por isso, ele pode afirmar que existe um "Marx após Freud". Essa noção de temporalidade na história do pensamento é também aplicada à análise da própria sociedade.

Seguindo raciocínio semelhante, a historiadora Virgínia Fontes apresenta uma abordagem sobre a categoria freudiana de conflito, relacionando-a com a análise histórica:

Embora tenha papel e função definidos, o conflito intrapsíquico, em Freud, tem conteúdos de dois tipos: No primeiro, um elemento da psique - o isso ou o id - tem um conteúdo que, enquanto tal, é inacessível e, a rigor, sequer é formulável de maneira sistemática. Ele figura como uma espécie de tensionador permanente, embora não seja possível alterá-lo ou modificá-lo. O segundo tipo de conteúdo, ao contrário, é aberto ao processo histórico e à singularização: temos aqui o conflito entre as instâncias psíquicas que, simultaneamente, pode ser pensado como uma estrutura (com disposições tópicas) e como um processo, na medida em que seus conteúdos se alteram duplamente - segundo os momentos da existência singular (diferentes fases do amadurecimento e da vida) e segundo censuras ou rupturas que teriam cunho histórico (FONTES, 2005, p. 121-122).

Percebe-se claramente a diferença e a mudança de perspectiva radical que essa abordagem provoca entre o conceito de natureza humana que permeia a teoria de Fukuyama, a megalothymia, e o conceito trabalhado em Freud - o do conflito. Em relação ao primeiro, temos uma ideia de homem como um ser que quer sempre ser diferente e melhor que os demais. Quanto ao segundo, entende-se o homem de uma forma muito mais complexa, como um ser em constante conflito interno e externo. $\mathrm{Na}$ verdade, não há, em Freud, nenhuma definição de natureza humana, pois esse "constante conflito" coloca em perspectivas inúmeras possibilidades 
que podem, sempre, modificar os desejos, as insatisfações e as vontades do próprio homem. Ou seja, nada há aí de estático: "o conflito interno e entre os homens - externo e interno, que não é fortuito, mas permanente reproduz-se e assume formas diferenciadas de acordo com a época, modificando-se" (Ibid., p. 126).

Existe, então, um conflito que depende do meio externo, da cultura, da sociedade e das repressões impostas em cada época, ao mesmo tempo em que existe também um conflito independente, interno, que o homem carrega através de suas gerações, dos traumas e problemas impostos às gerações passadas. Mas de que forma podemos pensar esse conflito sob a perspectiva da relação entre natureza e cultura, ou da própria transformação social?

Ressalte-se que tal concepção de conflito atribui a ele e à sua existência estrutural a possibilidade de mudança. Com isso, a própria estrutura psíquica abre-se para o futuro, isto é, comporta uma possibilidade de alteração da situação efetiva, presente e, portanto, de produção histórica do indivíduo (Ibid., p. 129).

A possibilidade de mudança é intrínseca ao homem e, consequentemente, à história. Isso se dá pelo constante conflito em que se encontra a estrutura psíquica do sujeito, e por este conflito ser impossível de ser superado e, até mesmo, harmonizado por longo período.

Mais adiante, Virgínia Fontes conclui:

Um ideal fusional do homem com o cosmo, um sentimento "oceânico" que eliminaria todos os conflitos e as dúvidas, que instauraria um mundo edênico e sem impulsos ou riscos, fica definitivamente eliminado pela reflexão freudiana. Nesse sentido, sua contribuição é decisivamente histórica: não há fim da história possível, não há apaziguamento final, mas processo permanente, tensão que se reinstala no momento que se acalma (Ibid., p. 130).

Finalmente, se a história é um processo contínuo, em que sentido é possível dar crédito a uma tese que proclama o seu fim e, em consequência, o fechamento dessa mesma história? A complexidade do sujeito e de suas reações aos problemas sociais não permitem nenhuma afirmação definitiva sobre a história.

Da mesma forma que a dissolução da URSS demonstrou que não basta a um país declarar-se socialista para que o capitalismo seja definitivamente superado, as constantes e diversificadas crises pelas quais passa o capitalismo atestam que a humanidade ainda pode vislumbrar outras formas de organização socioeconômica.

Neste trabalho, a partir de uma perspectiva marxista, intentei demonstrar as incoerências das justificativas sobre alguma etapa final da história, tanto no sentido do capitalismo quanto do comunismo, o que traz 
como consequência a análise e problematização constante sobre a sociedade em que vivemos e às possibilidades que ela nos permite. 


\section{Referências bibliográficas}

FONTES, Virgínia. Reflexões im-pertinentes: História e capitalismo contemporâneo. Rio de Janeiro: Bom Texto, 2005.

FUKUYAMA, Francis. O fim da história e o último homem. Trad. Aulyde S. Rodrigues. São Paulo: Rocco, 1992.

MARX, Karl; ENGELS, Friedrich. Manifesto Comunista. Tradução: Álvaro Pina. São Paulo: Boitempo, 1998.

MARX, Karl. A ideologia alemã. Tradução: Luciano Cavini Martorano; Nélio Schneider; Rubens Enderle. São Paulo: Boitempo, 2007. Manuscritos Econômico-Filosóficos. Trad. Jesus Ranieri. São

Paulo: Boitempo, 2004.

OLIVEIRA, Cláudio. "Economia marxista e economia freudiana ou política e pulsão". Crítica Marxista, São Paulo, v. 27, p. 47-63. 2008.

OLIVEIRA, Cláudio. "Freud, Marx e a Weltanschauungen". In: 10X Freud. Org. Ângela C. Bernardes. Rio de Janeiro: Azougue editorial, 2005.

Autor(a) para correspondência: Roberto Nunes Junior, Universidade Federal de Pernambuco, Centro de Filosofia e Ciências Humanas, Cidade Universitária, CEP 50740540, Recife - PE, Brasil. jr.robertonunes@gmail.com 